УДК 316.442(47+57)

\title{
СТАТУСНАЯ РАССОГЛАСОВАННОСТЬ КАК ФАКТОР НЕУДОВЛЕТВОРЕННОСТИ ЖИЗНЬЮ В РОССИЙСКОМ ОБЩЕСТВЕ
}

\author{
Петренко Георгий Максимович 1 , \\ georgiy.petrenk@gmail.com \\ Петренко Максим Степанович 2,3 , \\ petmaxim@yandex.ru \\ 1Национальный исследовательский университет «Высшая школа экономики», \\ Россия, 101000, г. Москва, ул. Мясницкая, 20 \\ ${ }^{2}$ Новосибирский государственный университет экономики и управления, \\ Россия, 630099, г. Новосибирск, ул. Каменская, 52/1 \\ 3Новосибирский юридический институт (филиал) \\ Томского государственного университета, \\ Россия, 630099, г. Новосибирск, ул. Советская, 7
}

Петренко Георгий Максимович, магистрант факультета социальных наук Национального исследовательского университета «Высшая школа экономики».

Петренко Максим Степанович, кандидат исторических наук, доцент кафедры мировой экономики, международных отношений и права Новосибирского государственного университета экономики и управления; доцент кафедры общественных наук Новосибирского юридического института (филиала) Томского государственного университета.

Рост социальной напряженности в России, усилившееся недовольство властью заставили ряд исследователей обратиться к изучению социальной структуры российского общества. Особый интерес вызывает теория статусной кристаллизации, согласно которой причиной многих социальных проблем является наличие в обществе статусных рассогласований. В современной социологической науке нет единого мнения относительно влияния статусной рассогласованности на социальное самочувствие населения и их удовлетворенность жизнью. На Западе долгое время доминировали исследования, обнаруживающие отрицательную зависимость между благополучием и наличием статусной рассогласованности. В этой связи возникает необходимость взглянуть на ситуацию, сложившуюся в России. Цель работы: анализ субъективных статусных рассогласований в иерархиях богатства, власти, престижа среди населения России в контексте концепции статусной кристаллизации и выявление связей между рассогласованием статусов и удовлетворенностью жизнью. Эмпирической базой исследования послужили данные «Российского мониторинга экономического положения и здоровья населения НИУ ВШЭ (RLMS-HSE)». Масштаб и структура статусных рассогласований были определены посредством сопоставления позиций индивида в обозначенных социальных иерархиях. Для анализа связи статусной кристаллизации и удовлетворенности жизнью использовались логистическая регрессия и коэффициент Крамера. Результаты: уровень статусной рассогласованности в современном российском обществе весьма значительный, однако связь между субъективным статусным рассогласованием и удовлетворенностью жизнью оказалась предельно мала. Некоторая зависимость была обнаружена между несоответствием уровня профессионального мастерства и вознаграждения, с одной стороны, и удовлетворенностью - с другой. Вывод: статусные рассогласования не оказывают существенного влияния на удовлетворенность жизнью в российском обществе, в котором существует неопределенная социальная структура, и благополучие человека зависит от множества других факторов.

Ключевые слова: Статус, статусная кристаллизация, статусная рассогласованность, удовлетворенность жизнью, социальное благополучие, богатство, власть, престиж. 
Проблема статусной рассогласованности, широко известная за рубежом, в последнее время привлекает внимание и российских специалистов. Само понятие статусной рассогласованности сложилось в рамках концепции статусной кристаллизации, согласно которой высокая степень кристаллизации социального статуса имеет место в случае согласованности статусов индивида в различных социальных иерархиях, в то время как низкая степень кристаллизации - в случае существенных различий позиций индивида в них [1]. Как писал П.А. Сорокин, «самые богатые далеко не всегда находятся у вершины политической или профессиональной пирамиды, также и не во всех случаях бедняки занимают самые низкие места в политической и профессиональной иерархии. Это значит, что взаимозависимость трех форм социальной стратификации далека от совершенства, ибо различные слои каждой из форм не полностью совпадают друг с другом» [2, с. 58-59]. Состояние, в котором наблюдается низкая степень статусной кристаллизации, обозначается также терминами «статусная рассогласованность» или «статусная неконсистентность». Эти понятия, хотя и отличаются некоторыми смысловыми оттенками, достаточно близки по смыслу [3], поэтому в настоящем исследовании используются как синонимы.

Одним из важнейших постулатов концепции статусной кристаллизации является утверждение о том, что степень кристаллизации социального статуса индивида может выступать фактором, определяющим его поведение и установки [1]. Практический интерес к изучению статусной рассогласованности связан с тем, что увеличение ее масштабов может стать причиной серьезных социальных проблем или обострения существующих противоречий [4]. Несовпадение статусов порождает потребность уровнять их посредством восхождения по социальной лестнице. Возникает чувство несправедливости и разочарованности, что может привести к повышению эмиграционной активности, росту протестных настроениях среди населения и социальным потрясениям.

Заключения такого рода, по сути, восходят еще к теории революции К. Маркса, который прямо не говорил о статусных рассогласованиях, но косвенно поднимал данную тему. По Марксу, революции происходят тогда, когда существующие производственные отношения, выражающиеся в социально-классовой структуре общества, вступают в противоречие с уровнем развития производительных сил [5]. Последние в первую очередь представляют людей, занимающих ведущие позиции в наиболее динамично развивающихся отраслях экономики. Другими словами, революции, по мнению Маркса, возникают тогда, когда прежние господствующие классы общества, сохраняя ведущие политические позиции, теряют прежнее экономическое влияние, а новые экономически сильные социальные группы, не имея возможности участвовать в принятии важнейших государственных решений, испытывают недовольство и становятся силой, дестабилизирующей общество и влекущей массы к революции. Таким образом, к революции ведут не столько обнищание простых людей и понижение их статуса, сколько рассогласованность позиций в экономических и политических иерархиях, что стало главным фактором неудовлетворенности буржуазии в период бурных потрясений XVI-XIX вв.

Родоначальником современной концепции статусной неконсистентности считается Герхард Ленски, который первым ввел в научный оборот понятие «status inconsistency». Он также установил связь между степенью статусной кристаллизации и политическими установками избирателей. Ленски обнаружил, что в каждой избирательной кампании в США доля голосовавших за Демократическую партию была значительно больше в низкоконсистентной категории, чем в высококонсистентной [6]. 
На поведение и установки индивида также влияет несоответствие между инвестициями (образование, уровень профессионального мастерства) и вознаграждением (доход, власть). Примером статусных рассогласований может выступать ситуация, когда человек обладает высоким уровнем образования, но занимается низкоквалифицированным видом деятельности или получает низкий доход. Особенно актуальна данная проблема в российском обществе, где неконсистентность образовательного и экономического статусов выражена наиболее явным образом [7]. Как правило, человек ожидает, что большие инвестиции в образование «окупятся» и обеспечат в будущем хорошую работу, высокий доход, а также соответствующий социальный статус. Однако это не всегда происходит. В ситуацию могут вмешаться внешние факторы. Например, когда на рынке труда представлено слишком много людей с одинаковой квалификацией, претендующих на одну и ту же работу, или личные причины (болезнь, несчастный случай). Дж. Гешвендер утверждал, что люди, которых условно можно отнести к «недооплачиваемым», будут испытывать чувства обиды и гнева из-за дисбаланса инвестиций и вознаграждения, в то время как «переплачиваемые» часто испытывают чувство вины. Но только люди, испытывающие дефицит вознаграждения, склонны участвовать в общественных движениях с целью изменить свое социальное положение [8]. Эти выводы подкрепляются теориями относительной депривации, референтных групп и теориями революции [9].

Важно различать объективную и субъективную стороны статусных рассогласований. Большинство ученых однозначно отдают предпочтение второй стороне, поскольку осознанное поведение индивида должно быть как-то мотивировано. Чтобы статусная неконсистентность влияла на поведение и установки индивида, человек должен осознавать факт статусной рассогласованности. Впервые такую идею выдвинули Д. Келли и У. Чемблиш [10], предположив, что именно сознание носителя рассогласованных статусов выступает решающим фактором при прогнозировании его поведения, тем более что человек может не разделять нормативные ожидания социальной группы, на какой ступени он должен находиться по тем или иным параметрам. Тогда объективное несоответствие статусов может не привести к субъективному статусному несоответствию. Иными словами, рассогласование статуса будет влиять на поведение человека только в том случае, когда им осознается это рассогласование. Позже к данной формулировке добавилось утверждение о том, что восприятие рассогласований должно иметь эмоциональный отклик в индивиде, чаще всего негативный. При этом статусная рассогласованность объективно может отсутствовать, но если рассогласования воспринимаются как реальные, то они будут реальны по своим последствиям, негативно влияя на психологическое состояние человека [11].

Проблема влияния статусной рассогласованности на психологическое самочувствие человека оказалась в поле исследования еще в 1960-1970-х гг. Внимание ученых было направлено на то, как статусная неконсистентность влияет на стрессовое состояние человека и какое поведение за этим следует. Так, Элтон Джексон утверждал, что статусная неконсистентность становится заметной для человека в случае несовпадения ожиданий и реальности. Низкая степень статусной кристаллизации индивида может стать причиной неуверенности в себе и заниженной самооценки, т. к. человеку сложно определить, насколько высоко его оценивают другие. В такой ситуации человек испытывает чувство неопределенности и разочарования, что неминуемо ведет к стрессу [12]. По результатам ряда исследований лица с некоторыми видами статусной неконсистентности могут иметь проблемы с психологическим самочувствием, что негативно сказывается на их удовлетворенности жизнью в целом [13]. В дальнейшем данный те- 
зис неоднократно подтверждался в ряде других исследований $[14,15]$. Так, Уильям Дресслер показал, что у людей, обнаруживших статусные рассогласования между образованием и профессиональным статусом, наблюдались симптомы депрессии [16].

Другим возможным последствием статусной несогласованности, как следует из теории статусной кристаллизации, является уход человека из социальной системы или возникновение у него чувства апатии. Это происходит потому, что несоответствие создает для человека ситуацию дискомфорта и затрудняет установление удовлетворяющих его отношений. Ленски также обнаружил, что люди, обладающие несогласованными статусами, менее склонны к взаимодействию с другими работниками в нерабочее время или со своими соседями. Они также реже участвуют в добровольных ассоциациях [17]. Дж. Гиббс и У. Мартин связали увеличение числа самоубийств с конфликтом ролевых ожиданий, которые ведут к стрессу, апатии, замкнутости [18].

На неудовлетворенность жизнью предположительно может влиять не только недооценка человека, но и получение им более высокого вознаграждения, чем тот уровень квалификации и образования, который он имеет. Как показали проведенные на Западе исследования, индивиды, имевшие высокий доход, но относительно низкий уровень образования и профессиональных навыков, получили высокие баллы по шкале Кесслера, что указывает на наличие у них психологического расстройства. Те же, кто имел высшее образование и высокий уровень квалификации, но меньший доход, напротив, не демонстрировали симптомов стресса [19]. Это объясняется существованием прочной зависимости состояния психологического комфорта от окружающей социальной среды. Постоянное взаимодействие с людьми не своего круга, тем более отличающимися более продуктивными показателями, осознание своей неспособности соответствовать интеллектуальным, профессиональным требованиям, предъявляемым занимаемому статусу, порождает чувство дискомфорта, которое не может быть компенсировано более высоким вознаграждением.

В разных культурах важность статусов воспринимается по-разному; ценности, сложившиеся в различных социальных группах, могут не совпадать даже внутри одного общества. Материальное благополучие само по себе в отрыве от социального взаимодействия, которое неизбежно возникает в процессе профессиональной деятельности, не имеет самостоятельной ценности, поскольку деньги всегда остаются лишь средством удовлетворения социальных потребностей. К тому же в описываемой ситуации трудно выйти на самореализацию индивида. Высокий доход привлекателен во многом из-за того, что он является своеобразным маркером собственной успешности и позволяет ощущать собственную значимость. Но высокий статус сам по себе ничего не значит без соответствующего признания группой и субъективного ощущения высоты положения. Это и отсутствует в ситуации рассогласования неоправданно высокого дохода и низкого уровня профессиональной подготовки. При этом обратная ситуация, когда признанный профессионализм не сопровождается достойным вознаграждением, не способствует формированию чувства неполноценности, особенно когда человек не рассматривает материальное благополучие как мерило интеллектуального и профессионального развития. Авторитет среди коллег сам по себе способен удовлетворить амбиции и повысить самооценку [13]. Следовательно, локальное признание индивида, его субъективное восприятие значимости в мы-группе является более важным, чем приписанная извне престижность.

В русле западных исследований работают и российские ученые, также обнаружившие взаимосвязь между статусной рассогласованностью и неудовлетворенностью своим социальным положением. Г.П. Бессокирная пишет, что с ростом степени статусной кристаллизации в целом увеличивается удовлетворенность своей жизнью [3]. 
Н.Д. Коленникова также обнаруживает прямую связь между неудовлетворенностью жизнью и низкой субъективной статусной консистентностью [20]. При этом объективная неконсистентность работающих россиян положительно влияет на восприятие их собственной жизни [20]. Солидаризируясь с общими выводами Г. Ленски и Дж. Гешвендера, российские исследователи прямо указывают, что рассогласование статусов ведет к росту социальной напряженности в России и массовым недовольствам $[3,20,21]$. В этой связи большой интерес представляет изучение статусных рассогласований в современном российском обществе. По данным Всероссийского центра изучения общественного мнения (ВЦИОМ) в России наблюдается рост недовольства действиями властей и нарастает уровень общественной тревожности, сопоставимый с уровнем 1993 и 1998 гг. [22]. По мнению многих оппозиционно настроенных политиков, политологов и журналистов, Россия находится на грани социального взрыва. Существует ли какая-либо связь между статусными рассогласованиями и усилением чувства социальной неудовлетворенности?

\section{Эмпирическая база исследования}

Эмпирической базой исследования являются данные «Российского мониторинга экономического положения и здоровья населения НИУ ВШЭ (RLMS-HSE)» [23]. Они позволяют получить информацию о статусах богатства, власти и уважения, как это оценивается самим индивидом, а также их удовлетворенность жизнью. Значимость этих измерений неоднократно подтверждалась социологами при анализе социальной структуры российского общества, а изучение субъективной стороны статусных рассогласований давно стало общим местом среди исследователей, занимающихся данным вопросом [1].

Данные мониторинга также позволяют изучить согласованность инвестиций, рассматриваемых как уровень профессионального мастерства индивида, и вознаграждений (богатство, власть). Здесь содержатся результаты опросов, в которых респондентам необходимо было оценить свои позиции в иерархиях власти, дохода и престижа. Каждая шкала имела девять ступеней. Важно отметить, что вопросы шли один за другим, т. е. респондент мог держать в голове ответы, и неодинаковое расположение на трех шкалах можно рассматривать как свидетельство осознанности индивидом своей статусной позиции. В нашем исследовании несовпадения статусов считаются существенными, если разница рангов индивида по двум измерениям была больше либо равна трем. Например, если положение индивида в иерархии власти оценивалось на 2, а в иерархии богатства на 6, то мы имеем дело со статусной рассогласованностью, т. к. разность между 6 и 2 больше трех.

Кроме того, RLMS-HSE позволяет отследить повседневную жизнь людей в течение длительного времени, что открывает возможности не только для статического, но и динамического анализа. Для оценки взаимосвязи статусных рассогласований в динамике были использованы несколько временных точек: 2007, 2008, 2014, 2015, 2018 и 2019 гг.

Выбор этих годов связан с тем, что в периоды социальных потрясений возрастает вероятность увеличения разрыва между социальными статусами индивида. В указанные годы Россия переживала разной глубины экономические кризисы, характеризующиеся нарастанием социальных проблем и существенным сокращением доходов значительной части населения. Реальные доходы населения на протяжении 2007-2018 гг. были крайне изменчивы. Так, согласно данным Росстата, в 2007 г. рост реальных доходов составил 10,4 \%. В 2008 г. данный показатель был уже в четыре раза меньше. Наиболее драматическим оказались 2014 и 2015 гг., когда впервые за рассматриваемый период прирост реальных доходов населения стал отрицательным (табл. 1) [24]. 
Таблища 1. Реальные располагаемые денежные доходы населения Российской Федерации

Table 1. Real disposable monetary income of the population of the Russian Federation

\begin{tabular}{|c|c|}
\hline $\begin{array}{c}\text { Год } \\
\text { Year }\end{array}$ & $\begin{array}{c}\text { Изменение реальных доходов к предыдущему году, \% } \\
\text { Change in real income to the previous year, } \%\end{array}$ \\
\hline 2007 & 10,4 \\
\hline 2008 & 2,4 \\
\hline 2013 & 4 \\
\hline 2014 & $-0,7$ \\
\hline 2015 & $-3,2$ \\
\hline 2018 & $-0,1$ \\
\hline
\end{tabular}

Рассмотрение статусных рассогласований проводилось с двух сторон:

1. Статусные рассогласования на основе сопоставления положения индивида в иерархиях власти, богатства и престижа. Для определения масштабов статусных рассогласований были выделены те индивиды, чье положение хотя бы в одной из иерархий отличалось от занимаемой им позицией в двух других. Кроме этого, был проведен анализ парной статусной рассогласованности, т. е. рассмотрены конкретные статусные конфигурации: богатство-власть, богатство-уважение, власть-уважение, а также изучены направления рассогласований.

2. Статусные рассогласования с точки зрения баланса «инвестиции-вознаграждение». Степень статусной консистентности определялась через соотнесение позиций респондентов на идентификационных лестницах распределяемого вознаграждения (богатство, власть) и профессионального мастерства, рассматриваемого как инвестиция.

\section{Результаты анализа статусной кристаллизации в России}

В табл. 2 представлена динамика изменения статусов населения в шкалах «Богатство», «Власть» и «Престиж». Приведены следующие характеристики: среднее значение (сумма значений, деленная на число наблюдений), медиана (число, которое делит распределение пополам), мода (наиболее часто встречающееся значение).

Таблица 2. Характеристика социальных статусов населения в разные годы Table 2. Characteristics of the social status of people in different years

\begin{tabular}{|c|c|c|c|c|c|c|}
\hline $\begin{array}{l}\text { Шкалы и характеристики } \\
\text { Scales and characteristics }\end{array}$ & 2007 & 2008 & 2014 & 2015 & 2018 & 2019 \\
\hline \multicolumn{7}{|c|}{ Богатство/Wealth } \\
\hline Среднеe/Average & 3,90 & 4,05 & 4,02 & 4,02 & 3,98 & 3,98 \\
\hline Медиана/Median & 4,00 & 4,00 & 4,00 & 4,00 & 4,00 & 4,00 \\
\hline Мода/Fashion & 4 & 5 & 5 & 4 & 3 & 4 \\
\hline \multicolumn{7}{|c|}{ Власть/Power } \\
\hline Среднеe/Average & 3,65 & 3,79 & 3,92 & 3,99 & 4,00 & 4,03 \\
\hline Медиана/Median & 4,00 & 4,00 & 4,00 & 4,00 & 4,00 & 4,00 \\
\hline Мода/Fashion & 3 & 3 & 5 & 5 & 3 & 5 \\
\hline \multicolumn{7}{|c|}{ Престиж/Prestige } \\
\hline Среднеe/Average & 6,02 & 6,08 & 6,23 & 6,26 & 6,24 & 6,32 \\
\hline Медиана/Median & 6,00 & 6,00 & 6,00 & 6,00 & 6,00 & 6,00 \\
\hline Мода/Fashion & 5 & 5 & 7 & 7 & 7 & 7 \\
\hline
\end{tabular}


На основе анализа данных можно сделать предварительный вывод, что медианные значения в рассматриваемый период не менялись. Также мы видим, что средние значения довольно устойчивы и не претерпевают значительных изменений в изучаемые годы. Однако мы наблюдаем небольшие изменения модального значения. Так, в пяти временных точках из шести большинство людей оценивало свое положение в иерархии богатства на 4 или 5 (т. е. располагали себя в середине социальной лестницы). При этом в 2018 г. модальное значение в данной шкале стало равняться 3, что может означать одно из двух: либо люди стали более критически оценивать уровень своего материального положения, либо, что более вероятно, доходы населения снизились. Так или иначе, но большинство людей в 2018 г. оценили свое положение в измерении богатства ниже среднего.

В измерении власти статус индивидов менялся более значительно. Большинство людей оценивало свой объем власти либо как средний (5 из 9), либо ниже среднего (3 из 9). Несколько иная ситуация наблюдается в иерархии престижа (уважения). Здесь мы видим, что большинство людей не склонно оценивать себя как «неуважаемых» и потому модальное значение равно 5 (в 2007 и 2008 гг.) и 7 (в 2014, 2015, 2018, 2019 гг.).

Полученные выводы подтверждаются в табл. 3. Мы видим, что на лестницах богатства и власти большинство людей оценило свое статусное положение как среднее. При этом стоит сказать, что группа людей с низкими статусными позициями по двум данным измерениям также довольно многочисленна. В измерении власти численность людей, определяющих свое положение как низкое, в 2007 и 2008 гг. практически равняется числу людей, которые поставили себя в середину лестницы власти. Доля людей, которые считали себя богатыми, довольно малочисленна и не превышает 5,1 \% от всей совокупности (2018 г.). То же самое можно сказать про тех, кто полагал, что обладает большим объемом власти. Эта группа также является самой малочисленной, и доля людей, входящих в нее, не превышает 7,4% (2018 г.).

Обратившись к лестнице престижа, мы обнаружим, что здесь ситуация существенно отличается. Несмотря на то, что большая часть людей определила степень уважения к себе как «среднюю» (за исключением 2018 и 2019 гг.), доля людей, распределившихся внизу иерархической лестнице, сильно сократилась по сравнению с предыдущими двумя шкалами. Значительная часть людей считает себя уважаемыми в обществе людьми, и только около 5-6 \% людей оценивают уважение к себе как «низкое».

таблица 3. Распределение респондентов по ступеням социальных лестниц богатства, власти и уважения, \%

Table 3. Distribution of respondents by the rungs of the social ladders of wealth, power and respect, \%

\begin{tabular}{|c|c|c|c|c|c|c|}
\hline Шкалы и ступени/Scales and steps & 2007 & 2008 & 2014 & 2015 & 2018 & 2019 \\
\hline \multicolumn{7}{|c|}{ Богатство/Wealth } \\
\hline Низшая/Inferior & 39,9 & 36,1 & 37,0 & 37,6 & 39,4 & 39,0 \\
\hline Средняя/Average & 56,4 & 58,9 & 58,5 & 57,9 & 55,5 & 56,9 \\
\hline Высшая/Highest & 3,7 & 5,0 & 4,4 & 4,5 & 5,1 & 4,1 \\
\hline \multicolumn{7}{|c|}{ Власть/Power } \\
\hline Низшая/Inferior & 47,5 & 45,1 & 41,4 & 40,2 & 41,2 & 38,5 \\
\hline Средняя/Average & 47,8 & 49,4 & 52,6 & 53,0 & 51,5 & 54,9 \\
\hline Высшая/Highest & 4,8 & 5,5 & 6,0 & 6,8 & 7,4 & 6,7 \\
\hline \multicolumn{7}{|c|}{ Престиж (уважение)/Prestige (respect) } \\
\hline Низшая/Inferior & 6,9 & 6,7 & 5,2 & 4,8 & 5,8 & 4,6 \\
\hline Средняя/Average & 50,8 & 50,9 & 48,4 & 48,4 & 46,6 & 46,0 \\
\hline Высшая/Highest & 42,2 & 42,4 & 46,4 & 46,8 & 47,6 & 49,3 \\
\hline
\end{tabular}


Стоит отметить, что распределение респондентов по ступеням социальных лестниц в периоды экономического спада не всегда претерпевает существенные изменения. Более того, вопреки ожиданиям, доля тех, кто относил себя к бедным в 2008 г., сократилась по отношению к предыдущему периоду, а тех, кто определял себя как человека со средним достатком или высоким, наоборот, возросла. После кризиса 2014 г. число людей, определявших себя, как бедных, ожидаемо стало расти, но так и не достигло уровня 2007 г.

Возвращаясь к проблеме статусной кристаллизации, важно посмотреть, наблюдаются ли у населения подлинные рассогласования. Результаты исследования представлены в табл. 4.

Таблища 4. Масштабы статусной рассогласованности в разные годы Table 4. Scale of status inconsistency in different years

\begin{tabular}{|l|c|c|c|c|c|c|}
\hline Количество респондентов/Number of respondents & 2019 & 2018 & 2015 & 2014 & 2008 & 2007 \\
\hline $\begin{array}{l}\text { Общее число респондентов (чел.) } \\
\text { Тоtal number of respondents (реорl) }\end{array}$ & 10198 & 10080 & 10452 & 10724 & 8420 & 8852 \\
\hline $\begin{array}{l}\text { Численность респондентов с кристаллизованными } \\
\text { статусами (чел.) } \\
\text { Number of respondents with crystallized statuses (people) }\end{array}$ & 7086 & 6965 & 7282 & 7488 & 5954 & 6079 \\
\hline $\begin{array}{l}\text { Доля статусно-консистентных людей (\%) } \\
\text { Share of status-соnsistent peорle (\%) }\end{array}$ & 69,5 & 69,1 & 69,7 & 69,8 & 70,7 & 68,7 \\
\hline
\end{tabular}

Из таблицы видно, что в изучаемые годы доля респондентов с кристаллизованными статусами богатства, власти и уважения находилась в пределах 68-71 \%. Предположение относительно увеличения статусных рассогласований в кризисные периоды не подтвердилось. Возможно, кризис становится причиной уменьшения кристаллизации статуса в уже рассогласованных группах, но не влияет на их масштабы. Либо эффекты кризиса проявляются не на суммарном показателе статусной консистентности (когда одновременно сравнивается положение индивида в трех иерархиях), а в конкретных парах статусов.

Рассмотрим согласованность рангов россиян в 2019 г. по трем парам статусов: «богатство-власть» (табл. 5), «богатство-престиж» (табл. 6), «власть-престиж» (табл. 7).

\section{Таблища 5. Рассогласованность рангов богатства и власти Table 5. Inconsistency of ranks of wealth and power}

\begin{tabular}{|l|c|c|}
\hline $\begin{array}{l}\text { Консистентность или рассогласованность рангов } \\
\text { Consistency or inconsistency of ranks }\end{array}$ & $\begin{array}{c}\text { Количество (чел.) } \\
\text { Number (people) }\end{array}$ & $\begin{array}{c}\text { Доля в совокупности (\%) } \\
\text { Share in total (\%) }\end{array}$ \\
\hline $\begin{array}{l}\text { Консистентность богатства и власти } \\
\text { Consistency of wealth and power }\end{array}$ & 9524 \\
\hline $\begin{array}{l}\text { Превышение уровня власти над уровнем богатства } \\
\text { Exceeding the level of роwer over the level of wealth }\end{array}$ & 297 \\
\hline $\begin{array}{l}\text { Превышение уровня богатства над уровнем власти } \\
\text { Exceeding the level of wealth over the level of power }\end{array}$ & 263 & 2,9 \\
\hline
\end{tabular}

В данной паре статусов процент согласованных рангов наибольший $(94,4$ \%). Это говорит о том, что абсолютное большинство людей считает, что их статусные позиции в иерархиях богатства и власти совпадают. Это можно объяснить тем, что данные социальные измерения часто оказываются взаимосвязанными: деньги могут конвертироваться во власть точно так же, как власть конвертируется в деньги. Только 2,2 \% поставили себя выше на лестнице богатства, чем на лестнице власти, и 2,9 \% считают наобо- 
рот, что их статусное положение в иерархии власти опережает статусное положение в иерархии богатства.

В свою очередь, гораздо меньше доля людей, у кого совпадают оценки своей позиции в двух других парах статусов: 56,3 \% в паре «богатство-престиж» и 58,7 \% в паре «власть-престиж».

Таблища 6. Рассогласованность рангов богатства и престижа Table 6. Inconsistency of ranks of wealth and prestige

\begin{tabular}{|l|c|c|}
\hline $\begin{array}{l}\text { Консистентность или рассогласованность рангов } \\
\text { Consistency or inconsistency of ranks }\end{array}$ & $\begin{array}{c}\text { Количество (чел.) } \\
\text { Number (people) }\end{array}$ & $\begin{array}{c}\text { Доля в совокупности (\%) } \\
\text { Share in total (\%) }\end{array}$ \\
\hline $\begin{array}{l}\text { Консистентность богатства и престижа } \\
\text { Consistency of wealth and prestige }\end{array}$ & 5583 & 56,3 \\
\hline $\begin{array}{l}\text { Превышение уровня престижа над уровнем богатства } \\
\text { Exceeding the level of prestige over the level of wealth }\end{array}$ & 4321 & 43,6 \\
\hline $\begin{array}{l}\text { Превышение уровня богатства над уровнем престижа } \\
\text { Ехсеeding the level of wealth over the level of prestige }\end{array}$ & 8 & 0,1 \\
\hline
\end{tabular}

На основании таблицы можно сделать вывод, что наблюдаемый дисбаланс вызван перекосом в сторону более высокой оценки индивидом уровня своего престижа, о чем уже говорилось выше. Примерно та же ситуация наблюдается в паре статусов «власть-престиж». Значительная часть людей считает $(41,2$ \%), что их положение на лестнице власти не соответствует их месту на лестнице престижа.

Таблица 7. Рассогласованность рангов власти и престижа Table 7. Inconsistency of ranks of power and prestige

\begin{tabular}{|l|c|c|}
\hline $\begin{array}{l}\text { Консистентность или рассогласованность рангов } \\
\text { Consistency or inconsistency of ranks }\end{array}$ & $\begin{array}{c}\text { Количество (чел.) } \\
\text { Number (people) }\end{array}$ & $\begin{array}{c}\text { Доля в совокупности (\%) } \\
\text { Share in total (\%) }\end{array}$ \\
\hline $\begin{array}{l}\text { Консистентность власти и престижа } \\
\text { Consistency of power and prestige }\end{array}$ & 5805 & 58,7 \\
\hline $\begin{array}{l}\text { Превышение уровня престижа над уровнем власти } \\
\text { Ехсеeding the level of prestige over the level of power }\end{array}$ & 4076 & 41,2 \\
\hline $\begin{array}{l}\text { Превышение уровня власти над уровнем престижа } \\
\text { Exceeding the level of power over the level of prestige }\end{array}$ & 7 & 0,1 \\
\hline
\end{tabular}

Проблема статусных рассогласований требует обращения к вопросу соответствия «инвестиций» человека и получаемых «вознаграждений» (табл. 8). В качестве инвестиций рассматривались затраты индивида на обретение определенных знаний и компетенций в профессиональной сфере. Объем вознаграждения в данном случае проявлялся в оценке индивидом своего положения в иерархиях богатства и власти. В выводах представлены четыре временные точки, т. к. в 2007 и 2019 гг. вопрос, касающийся профессионального мастерства опрашиваемого, не задавался.

Мы видим, что масштабы статусных рассогласований в четырех раундах довольно устойчивые. Только в 2015 г. наблюдается небольшое увеличение доли статуснонеконсистентного населения. Кроме того, около 30 \% людей отмечают наличие дисбаланса между «инвестициями» и «вознаграждением», а также утверждают, что при их уровне профессионального мастерства должны быть более богаты. Таким образом, в каждой временной точке мы наблюдаем порядка 30 \% населения, которое считает себя недооцененными. Только 1-1,5 \% считают, что их доходы превышают тот уровень, который соответствует их знаниям и компетенциям. 
Таблица 8. Динамика изменения дисбаланса «инвестиций» и «вознаграждений» (уровень профессионального мастерства и богатство), \%

Table 8. Dynamics of change in the discrepancy between «investments» and «rewards» (professional skills and wealth), \%

\begin{tabular}{|l|c|c|c|c|}
\hline $\begin{array}{l}\text { Консистентность или дисбаланс уровней профессионального мастерства и } \\
\text { богатства } \\
\text { Соnsistency оr discrepancy between professional skills and wealth }\end{array}$ & 2008 & 2014 & 2015 & 2018 \\
\hline $\begin{array}{l}\text { Консистентность уровня профессионального мастерства и богатства } \\
\text { Соnsistency of the level of professional ехсеllence and wealth }\end{array}$ & 69,1 & 71,0 & 67,8 & 70,1 \\
\hline $\begin{array}{l}\text { Превышение уровня профессионального мастерства над статусом богатства } \\
\text { Ехсеeding the level of professional skill over wealth status }\end{array}$ & 29,8 & 27,7 & 31,1 & 28,5 \\
\hline $\begin{array}{l}\text { Превышение статуса богатства над уровнем профессионального мастерства } \\
\text { Ехсеeding the status of wealth over the level of professional ехсеllence }\end{array}$ & 1,1 & 1,3 & 1,1 & 1,5 \\
\hline
\end{tabular}

В табл. 9 представлены масштабы консистентности профессионального мастерства и объема власти.

Таблица 9. Динамика изменения дисбаланса «инвестиций» и «вознаграждений» (уровень профессионального мастерства и власть), \%

Table 9. Dynamics of change in the discrepancy between «investments» and «rewards» (professional skills and power), \%

\begin{tabular}{|c|c|c|c|c|}
\hline $\begin{array}{l}\text { Консистентность или дисбаланс уровней профессионального мастерства и } \\
\text { власти } \\
\text { Consistency or Inconsistency between professional skills and power }\end{array}$ & 2008 & 2014 & 2015 & 2018 \\
\hline $\begin{array}{l}\text { Консистентность уровня профессионального мастерства и власти } \\
\text { Consistency of the level of professional excellence and power }\end{array}$ & 65,2 & 69,1 & 67,4 & 68,6 \\
\hline $\begin{array}{l}\text { Превышение уровня профессионального мастерства над статусом власти } \\
\text { Exceeding the level of professional skill over the status of power }\end{array}$ & 33,9 & 29,6 & 31,4 & 29,0 \\
\hline $\begin{array}{l}\text { Превышение статуса власти над уровнем профессионального мастерства } \\
\text { Exceeding the status of power over the level of professional skill }\end{array}$ & 1,0 & 1,2 & 1,2 & 2,4 \\
\hline
\end{tabular}

Из таблицы видно, что с 2008 г. масштабы статусных рассогласований претерпели некоторые изменения, но небольшие (разница в доле статусно-консистентных индивидов составляла порядка 3-4 \%). При этом большая часть людей с низкой степенью кристаллизации статуса считает себя скорее «недооцененными», чем «переоцененными». Доля людей, которые считают себя обладателями слишком большого объема власти, в 2018 г. составила лишь 2,4\%, в то время как в 2015 г. она была $1,2 \%$, а в 2008 г. - всего $1 \%$. Другими словами, приходится признать, что со временем постепенно увеличивается число тех, кто считает, что им доверено слишком много власти при их уровне компетенций.

Таким образом, в ходе изучения динамики изменения статусов населения в трех социальных иерархиях, а также масштабов распространенности статусных рассогласований, не было обнаружено подтверждений гипотезы о том, что в кризисные периоды рассогласованность статусов становится более ярко выраженной, результатом чего должно было явиться увеличение доли субъективно неконсистентных людей. Исходя из структуры статусных рассогласований, можно сделать вывод, что люди более склонны высоко оценивать себя в социальном измерении «престиж» и оценивать свое положение как среднее или ниже среднего в измерениях «власти» и «богатства». Кроме того, проведенный анализ показал, что около трети населения чувствуют дисбаланс между их уровнем профессионального мастерства и получаемым вознаграждением, выражающемся в уровне богатства и объеме власти. 
Рассматривая вопрос взаимосвязи статусных рассогласований и удовлетворенности жизнью, можно сделать вывод, что связь между этими двумя показателями есть, но довольно слабая (коэффициент Крамера равен 0,041, значимость на уровне 0,01). Результат получен на базе данных за 2018 г. Однако по другим годам ситуация примерно одинаковая. Люди, у которых наблюдается неконсистентность статусов в иерархиях богатства, власти и престижа, демонстрируют меньшую удовлетворенность жизнью, чем статусноконсистентные индивиды. Однако причина более низкой оценки удовлетворенности может быть обусловлена не уровнем статусной консистентности, а рядом других факторов, в том числе конкретным положением индивида в данных иерархиях. Например, страдать можно от большого объема ответственности, который ложится на плечи руководителей, от осознания невозможности реализации задуманного в рамках занимаемого положения, а не от рассогласования статусов. На удовлетворенность жизнью заметно влияет невротизм. И это влияние усиливается осознанием своего низкого социального статуса [25]. Ключевым фактором удовлетворенности жизнью является то, на какую ступень в социальной лестнице поставил индивид себя сам. Причем субъективная оценка может быть оторвана от реального положения дел, но именно она вносит больший вклад в самочувствие индивида.

Попарное сравнение статусной рассогласованности и удовлетворенности жизнью показывает более тесную связь, однако прирост незначительный. В паре рассогласований между богатством и властью коэффициент Крамера получился 0,054. Связь между удовлетворенностью жизнью и наличием рассогласований в измерениях «богатство-престиж (уважение)» еще меньше (коэффициент Крамера равен 0,048). Наиболее тесная связь между статусной неконсистентностью и неудовлетворенностью жизнью была обнаружена в паре «власть-престиж (уважение)». Здесь коэффициент Крамера оказался равен 0,061. Во всех трех парах коэффициенты значимы на уровне 0,001 .

Поскольку наиболее тесная связь наблюдается в паре «власть-престиж (уважение)», рассмотрим доли неудовлетворенных в трех группах. К первой группе отнесем тех, кто ставит собственный уровень власти выше уровня престижа (уважения). Неудовлетворенных жизнью среди таких оказалось 20 \%. В группе людей, у кого уровень престижа превышает уровень власти, доля неудовлетворенных жизнью несколько больше - 28,1\%. Наконец, третья группа - статусно-консистентные люди в паре «власть-престиж». Среди них доля неудовлетворенных - 21,6 \%. Таким образом, даже в условиях обделенности властью уважаемых людей говорить о прямой зависимости влияния статусной рассогласованности на удовлетворенность жизнью преждевременно, т. к. неудовлетворенных жизнью среди них немногим больше, чем среди статусно-консистентных людей.

Если обратиться к дисбалансу «инвестиций» и «вознаграждения» как фактору неудовлетворенностью жизнью, то здесь обнаруживается более высокая зависимость. Рассогласованность уровня профессионального мастерства и богатства отрицательно связана с удовлетворенностью жизнью (коэффициент Крамера $-0,11$, уровень значимости - 0,001). Среди статусно-консистентной группы доля людей, которые не очень удовлетворены или совсем не удовлетворены жизнью, составила 21,6 \%. В группе, куда попали люди с уровнем вознаграждения, превышающим уровень профессионального мастерства, не нашлось ни одного человека, который бы сказал, что совсем не удовлетворен своей жизнью. При этом доля людей, не очень удовлетворенных жизнью, составила 7,3\%. Как и ожидалось, наиболее недовольной группой оказалась та часть людей, у которых уровень инвестиций превышает уровень вознаграждения. Среди них почти треть $(32,1 \%)$ полностью или частично не удовлетворены жизнью. Однако и эти показатели нельзя считать ярко выраженными, тем более, что собственный уровень профессионализма человек может и переоценивать. 
Если в качестве вознаграждения рассматривать получаемый индивидом уровень власти, то статусная рассогласованность и удовлетворенность жизнью оказываются также связанными, однако теснота связи меньше (коэффициент Крамера - 0,096, уровень значимости - 0,001). Среди тех, у кого полученное «вознаграждение» сопоставимо с «инвестициями», доля неудовлетворенных жизнью составила 21,6 \%. Наибольшее число неудовлетворенных жизнью людей наблюдается среди тех, у кого инвестиции не окупились и получаемое вознаграждение (в данном случае уровень власти) не соответствует ожиданиям (доля неудовлетворенных - 31,9 \%). Если говорить о тех, у кого уровень власти «больше, чем полагается», то среди таких людей не удовлетворены жизнью 12,2% (табл. 10).

\section{Таблица 10. Доли неудовлетворенных жизнью при различных конфигурациях баланса «инвестиций» и «вознаграждения», \%}

Table 10. Shares of people dissatisfied with life in different configurations of the balance of «investment» and «reward», \%

\begin{tabular}{|l|c|c|}
\hline $\begin{array}{l}\text { Конфигурации баланса «инвестиций» и } \\
\text { «вознаграждения» } \\
\begin{array}{l}\text { Configurations of the balance of «invest- } \\
\text { ment» and «reward» }\end{array}\end{array}$ & $\begin{array}{c}\text { Уровень профессионального } \\
\text { мастерства - богатство } \\
\text { Professional skill level - wealth }\end{array}$ & $\begin{array}{c}\text { Уровень профессионального } \\
\text { мастерства - власть } \\
\text { Professional skill level - power }\end{array}$ \\
\hline $\begin{array}{l}\text { «Инестиции» paвны «вознаграждению» } \\
\text { «Investment» is equal to «reward» }\end{array}$ & 21,6 & 21,6 \\
\hline $\begin{array}{l}\text { «Инвестиции» превышают «вознаграж- } \\
\text { дение» } \\
\text { «Investments» exceed «reward» }\end{array}$ & 32,1 & 31,9 \\
\hline $\begin{array}{l}\text { «Инвестиции» меньше «вознаграждения» } \\
\text { «Investment» is less than «reward» }\end{array}$ & 7,3 & 12,2 \\
\hline
\end{tabular}

Таким образом, нельзя говорить о существовании прямой зависимости между рассогласованием социальных статусов и удовлетворенностью жизнью. Ее не обнаружили и в современном Китае [26]. Поиск корреляций между этими двумя переменными сам по себе сомнителен, поскольку на удовлетворенность жизнью влияет множество факторов. Некоторая связь была обнаружена только в паре «инвестициивознаграждение». По мере увеличения разрыва между ними неудовлетворенность жизнью нарастает. Однако несмотря на ухудшение экономического положения в стране после 2014 г. и увеличение разрыва между «инвестициями» и «вознаграждением», никакого нарастания недовольства обнаружено не было. Из табл. 11 видно, что удовлетворенность жизнью в 2014-2019 гг. была выше, чем в 2007-2008 гг.

таблица 11. Динамика удовлетворенностью жизнью в разные годы, \% Table 11. Dynamics of life satisfaction in different years, \%

\begin{tabular}{|l|c|c|c|c|c|c|}
\hline $\begin{array}{l}\text { Удовлетворены или не удовлетворены жизнью } \\
\text { Satisfied or dissatisfied with life }\end{array}$ & 2007 & 2008 & 2014 & 2015 & 2018 & 2019 \\
\hline Удовлетворены/Satisfied & 40,1 & 42,8 & 51,3 & 50 & 49,8 & 52,3 \\
\hline Не удовлетворены/Dissatisfied & 35,6 & 34,5 & 25 & 26,7 & 24,9 & 25,3 \\
\hline
\end{tabular}

На удовлетворенность жизнью в большей степени влияет не материальное положение индивида, а его субъективная оценка богатства в сравнении с другими людьми. При этом человек склонен занижать свою статусную позицию в категории богатства, если он относится к состоятельной части общества, поскольку сравнивает свое положение с узкой прослойкой сверхбогатых людей. В этом случае он завышает свои инвестиции и занижает отдачу от них. Люди небогатые зачастую делают наоборот. Они завышают свой 
статус в иерархии богатства, безосновательно относя себя к среднему классу, поскольку сравнивают свой уровень благополучия с наиболее обездоленной частью общества. Как справедливо пишет Н.Д. Коленникова, «современное российское общество характеризуется стремлением большинства населения субъективно оценивать себя как представителей «срединных» групп при объективно низком социальном статусе» [20, с. 158].

На основе логистической регрессии мы пришли к выводу, что на удовлетворенность жизнью в большей степени влияет не материальное положение индивида, а его субъективная оценка богатства в сравнении с другими людьми. Чем ниже человек оценивает свое место в иерархии, прежде всего в иерархии богатства, тем менее он удовлетворен. При этом фактическое неравенство доходов слабо влияет на степень удовлетворенности. Это подтверждают исследования по психологии счастья. Некоторая корреляция заметна лишь среди самых бедных и самых богатых слоев населения [26].

Человек ставит себя в иерархии богатства ниже значимых «других», когда данное измерение (богатство) для него самого значимо. В этом случае он скорее будет склоняться к недооценке своего уровня и, наоборот, будет переоценивать свой статус в незначимой для него иерархии или указывать ее произвольное значение, обычно среднее. Исключение составляют самые верхние группы, которые гордятся своим высоким положением в иерархии богатства, власти, но среди них практически нет лиц статусно-неконсистентных.

Субъективный аспект здесь имеет особое значение, поскольку допускает и обратную зависимость. Оценка своего места в иерархии богатства, власти, престижа сама по себе содержит элемент удовлетворенности. Индивид сравнивает себя с другими и оценивает свое положение в иерархии в зависимости от удовлетворенности своим положением. Человек склонен завышать уровень своих инвестиций и заявлять о занимаемом низком социальном статусе, если он не удовлетворен занимаемой статусной позицией. При этом неудовлетворенность может быть вызвана независимыми от социального статуса причинами, в том числе личного происхождения. Из работ психоаналитиков хорошо известно, что люди, страдающие неврозами, нередко связывают свое состояние раздражительности и неудовлетворенности с недостатком денег, власти. При этом увеличение богатства и повышение статуса у таких людей не приводит к снятию напряжения [27].

В основе убежденности о влиянии статусных рассогласований на удовлетворенность жизнью лежит идея обязательной саморефлексии и идентификация своих статусов в терминах согласованности или рассогласованности, что на практике встречается не так уж часто. Утверждения ученых, что статусная рассогласованность негативно влияет на психологическое самочувствие человека и толкает его на изменение своего статуса, в значительной степени строились на общей логике теоретических умозаключений. Так, встав на позиции ролевой теории личности, ученому приходилось идти до конца. Если поведение индивида обусловлено ожиданиями других, сложившееся на основе его социального статуса, то неизбежно должен возникнуть конфликт ожиданий в условиях статусной неконсистентности и, как следствие, ролевой конфликт $[12,28]$. В результате человек должен испытывать чувство неопределенности и тревогу. В таких случаях социальные отношения могут стать более напряженными, поскольку в сознании индивида не существует единой «Я-концепции» [29]. Осознание собственной статусной рассогласованности, несоответствия занимаемых статусов друг другу должны порождать внутреннее переживание. Когда в когнитивной структуре личности сталкиваются противоречивые знания, установки, убеждения, возникает состояние когнитивного диссонанса - расстроенного психологического состояния, вызывающего внутреннее напряжение, что естественным образом порождает желание его снизить путем изменения положения дел в обществе или в собственной жизни. 
Не случайно теория статусной кристаллизации неоднократно подвергалась критике [30]. Тезис о том, что рассогласование статуса подрывает социальные отношения, эмпирически не был продемонстрирован. Утверждения Г. Ленски о том, что у людей, занимающих статусно-рассогласованные позиции, возникают проблемы в общении с другими [6], строятся скорее на простом умозаключении. Опровергая Ленски, К. Бауман представил данные о том, что представители среднего класса с рассогласованным статусом с большей вероятностью будут удовлетворены социальным взаимодействием и тем сообществом, в которое они входят, чем статусно-консистентные лица [31]. Некоторые эффекты, приписываемые Ленски несоответствиям статусов, могли быть вызваны также принадлежностью к этнической группе. Не случайно сам Ленски утверждал, что наиболее важными для объяснения голосования за демократов являются несоответствия, которые возникают между низким этническим статусом и высокими статусами в других категориях [6].

Концепции статусной кристаллизации не учитывали тот факт, что значимость тех или иных статусных позиций может варьироваться от одной социальной среды к другой [32]. Например, ученый может определять свой статус исходя из профессионального престижа (например, ученой степени) и гордиться им, тогда как предприниматели и рабочие оценивают свой статус, ориентируясь на уровень своего дохода и богатства [33]. Кроме того, различные аспекты статуса могут замещать друг друга в своем влиянии на благополучие, т. е. люди могут сосредоточиться на том статусном измерении, в котором занимают высокое положение и не учитывать те, в котором их статус ниже. Например, для людей с высоким статусом в иерархии богатства низкий статус в иерархии власти может иметь меньшее значение, и наоборот [34].

При изучении степени неудовлетворенности зачастую происходит смешение различных ее сторон. Недостаточное вознаграждение при высоком уровне мастерства, как показал ряд исследований, способно снизить уровень удовлетворенности своей работой и экономическим положением, но на общее субъективное благополучие не влияет [35].

На оценку занимаемого индивидом статуса, его удовлетворенности, стремление что-то изменить в своей жизни влияет множество факторов, число которых увеличивается при изучении обществ незападного типа. Исследования, проведенные среди населения Ирана, показали, что неудовлетворенность и стремление изменить социальные условия жизни вследствие рассогласования статусов смягчаются такими переменными, как религиозность, фатализм, возраст, бессилие, политическое мнение, зависимость от правящей власти [36]. В Китае, вопреки ожиданиям теоретиков, выяснилось, что несогласованность статусов, занимаемых индивидами, в частности несоответствие между властью и богатством, не вредит их психологическому благополучию и не подвигает людей на борьбу за смену политического режима [34].

Таким образом, характеристика статусных рассогласований с точки зрения ее влияния на удовлетворенность жизнью, социальные установки и поведение индивидов содержит ограниченный набор информации, поскольку на самооценку личности влияет множество факторов. Проведенное исследование позволяет сделать вывод, что статусные рассогласования не оказывают существенного влияния на удовлетворенность жизнью, либо нивелируются другими факторами. Говорить можно лишь о влиянии ощущения своего места в иерархии. Но это относится также к статусно-консистентной категории населения. На чувство удовлетворенности влияют вознаграждение, поощрение, окупаемость затрат. Связь между рассогласованием уровня профессионального мастерства и вознаграждением была обнаружена, но оказалась весьма слабой. 
Проблема усугубляется тем, что в России сложилось сложное переплетение сословной иерархии и элементов классовой дифференциации [37], что существенно мешает формированию четких групповых самоидентификаций на низовом и среднем уровнях. Как справедливо пишет С.Г. Кордонский, «сосуществование в одном социальном пространстве сословной и классовой структур (без внятных объяснений того, как они сосуществуют) ведет к формированию весьма своеобразной формы отечественной аномии: когда человек принимает на себя (не интегрируя) заведомо противоречивые и конфликтные определения своего сословного и рыночного статусов» [38]. Предъявляемые запросы на качество жизни, признание, доход зачастую строятся по самым разным основаниям. Значимость таких категорий, как образование, справедливость, предприимчивость, сила и др., существенно различается среди населения. Хотя именно значимость тех или иных характеристик, которые индивид обнаруживает у себя и у других, оказывается решающей в обосновании несправедливости и формировании чувства неудовлетворенности своим положением. Не случайно высокие доходы ряда предпринимателей нелегитимны в глазах значительной части населения, оценивающей материальное благополучие (свое и других) с точки зрения ценностей, незначимых в бизнесе. Теории статусной кристаллизации возникли в обществах с четкой социально-классовой структурой населения, где люди знают, какое положение они занимают, социально активны и готовы отстаивать интересы своей группы. В России и других странах незападного типа социальная структура общества совершенно иная, что делает экстраполяцию оценок статусной рассогласованности на российское общество сомнительной.

\section{СПИСОК ЛИТЕРАТУРЫ}

1. Богомолова Т.Ю., Саблина С.Г. Статусная рассогласованность как аспект социальной стратификации: Презентация классической концепции // Рубеж. - 1997. - № 10-11. - С. 58-67.

2. Сорокин П.А. Социальная стратификация и мобильность // Человек. Цивилизация. Общество. - М.: Политиздат, 1992. - С. 230-332.

3. Бессокирная Г.П. Статусная рассогласованность сельских жителей в реформирующейся России // Социологический журнал. - 2014. - № 1. - С. 55-71.

4. Романова Н.П. Феномен статусной неконсистентности // Вестник Забайкальского государственного университета. - 2009. - № 4. - С. 212-217.

5. Маркс К. К критике политической экономии // Сочинения. - М.: Государственное издательство политической литературы, 1959. - Т. 13. - С. 1-167.

6. Ленски Г. Статусная кристаллизация: невертикальное измерение социального статуса // Социологический журнал. - 2003. - № 4. - С. 126-140.

7. Прохода В.А. Образование в структуре статусной неконсистентности современного российского общества // Человек. - 2021. - Т. 32. - № 2. - С. 51- 64.

8. Geschwender J.A. Continuities in theories of status consistency and cognitive dissonance // Social Forces. 1967. - V. 46. - № 2. - P. 160-171.

9. Свищёва А.Н. Теории референтных групп и революции: общая теоретическая матрица относительной депривации // Вестник Московского университета. Серия 18 «Социология и политология». 2018. - T. 24. - № 3. - C. 24-40.

10. Kelly K.D., Chambliss W.J. Status consistency and political attitudes // American Sociological Review. 1966. - V. 31. - № 3. - P. 375-382.

11. Status inconsistency and mental health: a random effects and instrumental variables analysis using 14 annual waves of cohort data / A. Milner, Z. Aitken, A. Kavanagh, A. la Montagne, D. Petrie // Social Science \& Medicine. - 2017. - № 189. - P. 129-137.

12. Jackson E.F. Status consistency and symptoms of stress // American Sociological Review. - 1962. V. 27. - № 4. - P. 469-480.

13. Ashford S. Upward mobility, status inconsistency, and psychological health // The Journal of Social Psychology. - 1990. - V. 130. - № 1. - P. 71-76.

14. Marmot M. The status syndrome: how social standing affects our health and longevity. - NY.: Times Books, 2004. - 319 p. 
15. Status inconsistency and common mental disorders in the Israel-based world mental health survey / G. Gal, G. Kaplan, R. Gross, I. Levav // Social psychiatry and psychiatric epidemiology. - 2008. - V. 43. - № 12. P. 999-1003.

16. Dressler W.W. Social consistency and psychological distress // Journal of Health and Social Behavior. 1988. - V. 29. - № 1. - P. 79-91.

17. Lenski G.E. Social participation and status crystallization // American Sociological Review. - 1956. V. 21. - № 4. - P. 458-464.

18. Gibbs J.P., Martin W.T. Status integration and suicide: a sociological study. - Eugene: University of Oregon Press, 1964. - 225 p.

19. Biron M., Reuver R., Bamberger P. Status inconsistency: current and future perspectives on a classic notion // Academy of Management Proceedings. - 2015. - V. 2015. - № 1. URL: https://www.researchgate.net/publication/291375421_Status_Inconsistency_Current_and_Future_Perspectiv es_on_a_Classic_Notion (дата обращения 02.08.2021).

20. Коленникова Н.Д. Экономический, квалификационный и властный статусы в российском обществе: консистентность и тенденции изменений: дис. ... канд. соц. наук. - М., 2020. - 195 с.

21. Тихонова Н.Е. Средний класс в фокусе экономического и социологического подходов: границы и внутренняя структура (на примере России) // Мир России. - 2020. - Т. 29. - № 4. - С. 34-56.

22. Уровень тревожности и страхи россиян. Результаты экспертной онлайн-панели по общероссийскому опросу ВЦИОМ (5 волна). URL: http://club-rf.ru/images/files/5eb3bfd935d37.pdf?utm_source= Uralweb.ru\&utm_medium=CPC\&utm_campaign=ssylki_v_news (дата обращения 02.08.2021).

23. Данные обследования Российского мониторинга экономического положения и здоровья населения НИУ ВШЭ. URL: https://www.hse.ru/rlms/spss (дата обращения 02.08.2021).

24. Федеральная служба государственной статистики. Реальные располагаемые денежные доходы населения, оперативные данные. URL: https://rosstat.gov.ru/folder/13397?print=1 (дата обращения 02.08.2021).

25. The role of neuroticism and subjective social status in the relationship between perceived social support and life satisfaction / J. Han, X. Leng, X. Gu, Q. Li, Y. Wang, H. Chen // Personality and Individual Differences. - 2021. - V. 168. - № 6. URL: https://www.researchgate.net/publication/343981006_ The_role_of_neuroticism_and_subjective_social_status_in_the_relationship_between_perceived_social_sup port_and_life_satisfaction (дата обращения 02.08.2021).

26. Аргил М. Психология счастья. - СПб.: Питер, - 2003. - 271 с.

27. Фромм Э. Человек для самого себя. - М.: АСТ: АСТ МОСКВА, 2010. -350 с.

28. Sampson E. Status congruence and cognitive consistency // Sociometry. - 1963. - V. 26. - № 2. - P. $146-162$.

29. Goffman I.W. Status consistency and preference for change in power distribution // American Sociological Review. - 1957. - V. 22. - № 3. - P. 275-281.

30. Zimmermann E. «Bringing Common Sense Back In»: some neglected assumptions in status inconsistency theory and research // European Journal of Sociology. - 1978. - V. 19. - № 1. - P. 52-73.

31. Bauman K.E. Status inconsistency, satisfactory social interaction and community satisfaction in an area of rapid growth // Social Forces. - 1968. - V. 47. - № 1. - P. 45-52.

32. Anderson C., Hildreth J.A., Howland L. Is the desire for status a fundamental human motive? A review of the empirical literature // Psychological Bulletin. - 2015. - V. 141. - № 3. - P. 574-601.

33. Anderson C. The Local-Ladder Effect: social status and subjective well-being // Psychological Science. 2012. - V. 23. - № 7. - P. 764-771.

34. Jin L., Tam T., Tao L. Well-off but powerless? Status incongruence and psychological well-being in contemporary China // Social Science \& Medicine. - 2019. - V 235. URL: https://www.researchgate.net/ publication/334203712_Well-off_but_powerless_Status_incongruence_and_psychological_well-being_in_ contemporary_China (дата обращения 02.08.2021).

35. Voces C., Caínzos M. Overeducation as status inconsistency: effects on job satisfaction, subjective wellbeing and the image of social stratification // Social Indicators Research. - 2021. - № 153. - P. 979-1010.

36. Pakseresht S., Safari B. Status inconsistency and its political consequences (text in Persian) // Iranian Journal of Sociology. - 2013. - V. 14. - № 3. - P. 3-30.

37. Шкаратан О.И., Ястребов Г.А. Социально-профессиональная структура и ее воспроизводство в современной России. Предварительные итоги представительного опроса экономически активного населения России 2006 г. - М.: ГУ ВШЭ, 2007. - 92 с.

38. Кордонский С.Г. Сословная структура постсоветской России. - М.: Институт Фонда «Общественное мнение», 2008. - 216 с.

Поступила 03.08.2021 г. 
UDC 316.442(47+57)

\title{
STATUS INCONSISTENCY AS A FACTOR OF LIFE DISSATISFACTION IN RUSSIAN SOCIETY
}

\author{
Georgiy M. Petrenko1, \\ georgiy.petrenk@gmail.com \\ Maxim S. Petrenko 2,3, \\ petmaxim@yandex.ru \\ ${ }^{1}$ National Research University Higher School of Economics, \\ 20, Myasnitskaya street, Moscow, 101000, Russia \\ ${ }^{2}$ Novosibirsk State University of Economics and Management, \\ 52/1, Kamenskaya street, Novosibirsk, 630099, Russia \\ ${ }^{3}$ Novosibirsk Law Institute (branch) of Tomsk State University, \\ 7, Sovetskaya street, Novosibirsk, 630007, Russia
}

Georgiy M. Petrenko, a master's student, National Research University Higher School of Economics.

Maxim S. Petrenko, Cand. Sc., associate professor, Novosibirsk State University of Economics and Management; associate professor, Novosibirsk Law Institute (branch) of Tomsk State University.

The growth of social tensions in Russia and the increased dissatisfaction with the authorities have forced a number of researchers to study of the social structure of Russian society. Of particular interest is the theory of status crystallization, according to which the cause of many social problems is the existence of status inconsistency in society. In modern sociological science there is no consensus about the influence of status inconsistency on the social well-being of the population and their life satisfaction. For a long time, the works of Western researchers have confirmed the idea that there is a negative correlation between well-being and the presence of status inconsistency. In this regard, it is necessary to look at the situation in Russia. The aim of the study is to analyze subjective status inconsistency in the hierarchies of wealth, power and prestige among the Russian population in the context of the concept of status crystallization and to identify the relationship between status inconsistency and life satisfaction. The empirical basis of the study was the data of the «Russia Longitudinal Monitoring Survey of HSE (RLMS-HSE)». The scale and structure of status inconsistency were studied by comparing the positions of individuals in the indicated social hierarchies. Logistic regression and Cramer's coefficient were used to analyze the relationship between status crystallization and life satisfaction. Results. The level of status inconsistency in contemporary Russian society is quite high. However, the relationship between subjective status inconsistency and life satisfaction is extremely small. Some correlation was found between life satisfaction on the one hand, and the status inconsistency between the level of professional skills and the level of remuneration on the other. Conclusion status inconsistency do not have a significant impact on life satisfaction in Russian society, where there is an uncertain social structure, and human wellbeing depends on many other factors.

Key words: Status, status crystallization, status inconsistency, life satisfaction, social well-being, wealth, power, prestige.

\section{REFERENCES}

1. Bogomolova T.Yu., Sablina S.G. Statusnaya rassoglasovannost kak aspect sotsialnoy stratifikatsii: prezentatsiya klassicheskoy kontseptsii [Status inconsistency as an aspect of social stratification: Presentation of the classic concept]. Rubezh, 1997, no. 10-11, pp. 58-67. 
2. Sorokin P.A. Sotsialnaya stratifikatsiya i mobilnost [Social stratification and mobility]. Chelovek. Tsivilizatsiya. Obshchestvo [Man. Civilization. Society]. Moscow, Politizdat Publ., 1992. pp. 230-332.

3. Bessokirnaya G.P. Statusnaya rassoglasovannost selskikh zhiteley v reformiruyushcheysya Rossii [Status inconsistency of rural residents in reforming Russia]. Sotsiologicheskiy zhurnal, 2014, no. 1, pp. 55-71.

4. Romanova N.P. Fenomen statusnoy nekosistentnosti [The phenomenon of status inconsistency]. Vestnik Zabaykalskogo gosudarstvennogo universiteta, 2009, no. 4, pp. 212-217.

5. Marks K. K kritike politicheskoy ekonomii [To the critique of political economy]. Sochineniya. Moscow, Gosudarstvennoe izdatelstvo politicheskoy literatury, 1959, vol. 13. pp. 1-167.

6. Lenski G. Statusnaya kristallizatsiya: nevertikalnoe izmerenie sotsialnogo statusa [Status crystallization: a non-vertical dimension of social status]. Sotsiologicheskiy zhurnal, 2003, no. 4, pp. 126-140.

7. Prokhoda V.A. Obrazovanie v strukture statusnoy nekosistentnosti sovremennogo rossiyskogo obshchestva [Education in the structure of status inconsistency of modern Russian society]. Chelovek, 2021, vol. 32, no. 2, pp. 51-64.

8. Geschwender J.A. Continuities in theories of status consistency and cognitive dissonance. Social Forces, 1967, vol. 46, no. 2, pp. 160-171.

9. Svishcheva A.N. Teorii referentnykh grupp i revolyutsii: obshchaya teoreticheskaya matritsa otnositelnoy deprivatsii [Reference group theories and revolutions: a general theoretical matrix of relative deprivation]. Vestnik Moskovskogo universiteta. Seriya 18 «Sotsiologiya i politologiya», 2018, vol. 24, no 3, pp. 24-40.

10. Kelly K.D., Chambliss W.J. Status consistency and political attitudes. American Sociological Review, 1966, vol. 31, no 3, pp. 375-382.

11. Milner A., Aitken Z., Kavanagh A., La Montagne A., Petrie D. Status inconsistency and mental health: A random effects and instrumental variables analysis using 14 annual waves of cohort data. Social Science \& Medicine, 2017, no 189, pp. 129-137.

12. Jackson E.F. Status consistency and symptoms of stress. American Sociological Review, 1962, vol. 27, no. 4 , pp. 469-480.

13. Ashford S. Upward mobility, status inconsistency, and psychological health. The Journal of Social Psychology, 1990, vol. 130, no 1, pp. 71-76.

14. Marmot M. The status syndrome: how social standing affects our health and longevity. New York, Times Books, 2004. 319 p.

15. Gal G., Kaplan G., Gross R., Levav I. Status inconsistency and common mental disorders in the Israel-based world mental health survey. Social psychiatry and psychiatric epidemiology, 2008, vol. 43, no. 12, pp. 999-1003.

16. Dressler W.W. Social consistency and psychological distress. Journal of Health and Social Behavior, 1988, vol. 29, no 1, pp. 79-91.

17. Lenski G.E. Social participation and status crystallization. American Sociological Review, 1956, vol. 21, no. 4, pp. 458-464.

18. Gibbs J.P., Martin W.T. Status integration and suicide: a sociological study. Eugene, University of Oregon Press, 1964. 225 p.

19. Biron M., Reuver R., Bamberger P. Status inconsistency: current and future perspectives on a classic notion. Academy of Management Proceedings, 2015, vol. 2015, no. 1. Available at: https://www.researchgate.net/publication/291375421_Status_Inconsistency_Current_and_Future_Perspectiv es_on_a_Classic_Notion (accessed 2 August 2021).

20. Kolennikova N.D. Ekonomicheskiy, kvalifikatsionny $i$ vlastny status v rossiyskom obshchestve: konsistentnost $i$ tendentsii izmeneniy. Dis. Kand. nauk [Economic, qualification and power statuses in Russian society: consistency and trends. Cand. Diss.]. Moscow, 2020. 195 p.

21. Tikhonova N.E. Sredniy klass v fokuse ekonomicheskogo i sotsiologicheskogo podkhodov: granitsy i vnutrennyaya struktura (na primere Rossii) [The middle class in the focus of economic and sociological approaches: borders and internal structure (on the example of Russia)]. Mir Rossii, 2020, vol. 29, no. 4, pp. 34-56.

22. Uroven trevozhnosti $i$ strakhi rossiyan. Rezultaty ekspertnoy onlayn-paneli po obshcherosiyskomu oprosu VTsIOM (5 volna) [The level of anxiety and fears of Russians. Results of the expert online panel on the allRussian survey by VCIOM (5 wave)]. Available at: http://club-rf.ru/images/files/5eb3bfd935d37. pdf?utm_source=Uralweb.ru\&utm_medium=CPC\&utm_campaign=ssylki_v_news (accessed 2 August 2021).

23. Dannye obsledovaniya Rossiyskogo monitoringa ekonomicheskogo polozheniya $i$ zdorovya naseleniya NIU VSHJE [Survey data from the Russian Monitoring of the Economic Situation and Health of the Population of the Higher School of Economics]. Available at: https://www.hse.ru/rlms/spss (accessed 2 August 2021).

24. Federalnaya sluzhba gosudarstvennoy statistiki. Realnye raspolagaemye denezhnye dokhody naseleniya, operativnye dannye [Federal State Statistics Service. Real disposable cash income of the population, operational data]. Available at: https://rosstat.gov.ru/folder/13397?print=1 (accessed 2 August 2021). 
25. Han J., Leng X., Gu X., Li Q., Wang Y., Chen H. The role of neuroticism and subjective social status in the relationship between perceived social support and life satisfaction. Personality and Individual Differences, 2021, vol. 168, no 6. Available at: https://www.researchgate.net/publication/343981006_The_role_of_neuro-ticism_and_subjective_social_status_in_the_relationship_between_perceived_social_support_and_life_ satisfaction (accessed 2 August 2021).

26. Argil M. Psikhologiya shchastya [The psychology of happiness]. St. Petersburg, Piter Publ., 2003. 271 p.

27. Fromm E. Chelovek dlya samogo sebya [Man for himself]. Moscow, AST, AST MOSKVA Publ., 2010. $350 \mathrm{p}$.

28. Sampson E. Status congruence and cognitive consistency. Sociometry, 1963, vol. 26, no 2, pp. $146-162$.

29. Goffman I.W. Status consistency and preference for change in power distribution. American Sociological Review, 1957, vol. 22, no. 3, pp. 275-281.

30. Zimmermann E. «Bringing Common Sense Back In»: some neglected assumptions in status inconsistency theory and research. European Journal of Sociology, 1978, vol. 19, no 1, pp. 52-73.

31. Bauman K.E. Status inconsistency, satisfactory social interaction and community satisfaction in an area of rapid growth. Social Forces, 1968, vol. 47, no. 1, pp. 45-52.

32. Anderson C., Hildreth J.A., Howland L. Is the desire for status a fundamental human motive? A review of the empirical literature. Psychological Bulletin, 2015, vol. 141, no. 3, pp. 574-601.

33. Anderson C. The local-ladder effect: social status and subjective well-being. Psychological Science, 2012 , vol. 23, no. 7, pp. 764-771.

34. Jin L., Tam T., Tao L. Well-off but powerless? Status incongruence and psychological well-being in contemporary China. Social Science \& Medicine, 2019, vol. 235. Available at: https://www.researchgate.net/publication/334203712_Well-off_but_powerless_Status_incongruence_and_ psychological_well-being_in_contemporary_China (accessed 2 August 2021).

35. Voces C., Caínzos M. Overeducation as status inconsistency: effects on job satisfaction, subjective wellbeing and the image of social stratification. Social Indicators Research, 2021, no. 153, pp. 979-1010.

36. Pakseresht S., Safari B. Status inconsistency and its political consequences (text in Persian). Iranian Journal of Sociology, 2013, vol. 14, no. 3, pp. 3-30.

37. Shkaratan O.I., Yastrebov G.A. Sotsialno-professionalnaya struktura i ee vosproizvodstvo v sovremennoy Rossii. Predvaritelnye itogi predstavitelnogo oprosa ekonomicheski aktivnogo naseleniya Rossii $2006 \mathrm{~g}$. [Social and professional structure and its reproduction in modern Russia. Preliminary results of a representative survey of the economically active population of Russia in 2006]. Moscow, GU VSHJE Publ., 2007. $92 \mathrm{p}$.

38. Kordonskiy S.G. Soslovnaya struktura postsovetskoy Rossii [The estate structure of post-Soviet Russia]. Moscow, Institut Fonda «Obshchestvennoe mnenie» Publ., 2008. 216 p.

Received: 3 August 2021. 